\title{
Propriedades coletivas, cooperativismo e economia solidária no Brasil
}

\section{Collectively owned properties, co-operativism and solidary economy in Brazil}

\author{
Edson Elias de Morais* \\ Fabio Lanza* \\ Luis Miguel Luzio dos Santos ${ }^{* *}$ \\ Silvia Schroeder Pelanda****
}

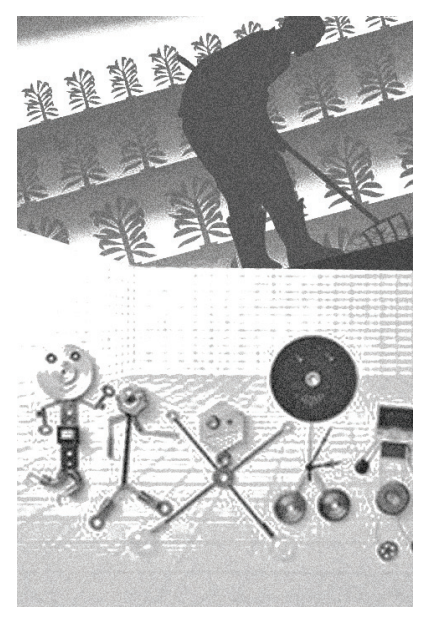

\begin{abstract}
Resumo: A discussão a seguir partiu das reflexões a respeito do desenvolvimento capitalista e a constituição das propostas atuais da economia solidária, que podem ser caracterizadas como uma forma de organização produtiva com autogestão, democracia participativa, sustentabilidade ambiental e promovem uma nova sociabilidade entre os sujeitos envolvidos. Os estudos são oriundos de investigações bibliográficas, bem como pesquisa de campo em experimento de economia solidária no meio rural na região noroeste do Paraná. Os resultados da observação, análises e interpretações indicam novas perspectivas, a partir da propriedade coletiva, para o enfrentamento das contradições oriundas do desenvolvimento capitalista.
\end{abstract}

Palavras-chave: Economia solidária. Trabalho e cooperativismo. Sociabilidade e propriedade coletiva.

* Bacharel em Teologia pela Faculdade Teológica Sul-Americana, acadêmico em Ciências Sociais pela Universidade Estadual de Londrina/PR, Brasil, bolsista de Iniciação Científica PIBIC/UEL, participante do GENTT, sob orientação do prof. dr. Fabio Lanza.

** Doutor em Ciências Sociais (PUC-SP), graduado em Ciências Sociais (Unesp-Araraquara), professoradjunto do Departamento de Ciências Sociais da UEL — Londrina/PR, Brasil.E-mail: lanza1975@gmail.com.

*** Doutor em Ciências Sociais (PUC-SP), graduado em Economia e Administração (UEL), professor-adjunto do Departamento de Administração da UEL — Londrina/PR, Brasil. E-mail: 1mig@uol.com.br.

**** Acadêmica em Ciências Contábeis, bolsista UEL — Londrina/PR, Brasil. Fund. Araucária sob orientação do prof. dr. Fabio Lanza. 


\begin{abstract}
The following discussion started about the reflections of capitalist development and the establishment of current proposals for Economic Partnership, which may be characterized as a form of productive organization with self-management, participatory democracy, environmental sustainability and promote a new sociability among the subjects involved. The studies are drawn from research literature, as well as field research in experimental social economy in rural areas in the northwestern region of Paraná. The results of observation, analysis and interpretations suggest new perspectives from the collective property, to confront the contradictions arising from capitalist development.
\end{abstract}

Keywords: Solidarity economics. Labour and cooperatives. Sociability and collective ownership.

\title{
1. Introdução
}

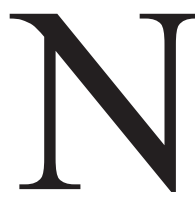

o decorrer dos séculos XVIII e XIX, frente ao avanço do capitalismo e às suas consequências perversas para grande parte da população, surgiram vários movimentos em torno de novas formas de produção e consumo que se pautavam por ideais de justiça social e solidariedade, que acabaram por ser nomeados como socialismo utópico. Mais recentemente, no último quarto do século XX, houve um revigoramento desses ideais, que resultaram em múltiplas alternativas que se encontram na busca por soluções contra a miséria, a exclusão, o desemprego e a cultura individualista dominante, ao que respondem com iniciativas balizadas em ideais de igualdade, cooperação e solidariedade, movimento que se tornou genericamente conhecido por economia solidária.

É verdade que cada período econômico da história humana apresentou seus obstáculos na distribuição das riquezas. Mas o capitalismo recente apresenta discrepâncias sociais abissais e em processo ascendente em todo o mundo, o que leva a consequências desastrosas para toda a humanidade.

O conceito de economia solidária não é, todavia, tão claramente delineado e possui diferentes perspectivas para o trato teórico na atualidade. Para Paul Singer (2005b, p. 11), a economia solidária é caracterizada como fruto do anseio de construir uma sociedade melhor do que a atual. E por esse motivo a economia solidária adapta-se aos princípios e valores de quem a aplica. Para o autor, essa diferença nos conceitos é positiva, pois estimula a troca de ideias e propostas.

Ainda, Singer confere à economia solidária uma função maior do que apenas uma resposta econômica à incapacidade do capitalismo de integrar todos 
seus membros ao mercado de consumo. Para o autor, a economia solidária pode ser uma "alternativa superior ao capitalismo", já que esta superioridade não deve ficar restrita ao plano econômico, mas sim em termos de qualidade de vida e de uma nova sociabilidade (Singer, 2008, p. 114).

\section{Perspectiva contemporânea do cooperativismo e economia solidária}

O grande projeto do socialismo do século XIX foi eliminar as classes sociais e propor uma nova sociedade, em que não houvesse a exploração do homem pelo homem, ou de uma classe pela outra, característica presente em toda a história da humanidade, como afirmam Marx e Engels (2007, p. 47): "A história de todas as sociedades até os nossos dias é a história de luta de classes". Na concepção marxiana as classes sociais, só serão eliminadas mediante o fim da propriedade privada. Na sua época (século XIX), em pleno desenvolvimento da segunda Revolução Industrial, a mobilização dos trabalhadores apresentava-se como a maior contradição frente à indústria capitalista e seus proprietários, em suas análises, a classe trabalhadora possui o potencial revolucionário em suas ações políticas para a tomada do poder de Estado, instalação da ditadura do proletariado como período transitório para o comunismo e, enfim, a eliminação das classe sociais.

Desde a Revolução Industrial (séculos XVIII e XIX), uma parte do movimento socialista procurou desenvolver estratégias que subvertesse o sistema capitalista e propôs um modelo de produção em que as sobras, e não salários, fossem partilhadas pelo grupo, ou cooperados, não havendo assim expropriação da mais-valia por parte do empresário capitalista. Nessa perspectiva socialista, é possível uma forma de organização de trabalho não capitalista, utilizando o modelo de produção industrial e de economia de mercado.

No entanto, na abordagem do socialismo científico se faz necessário uma organização política e uma ação revolucionária por parte da classe trabalhadora, atitudes que Marx não via nos primeiros socialistas — intitulados de utópi$\cos$-, sendo sua crítica contundente:

Suas proposições referentes à sociedade futura - como supressão do antagonismo entre cidade e campo, abolição da família, do lucro privado e do trabalho assalariado, proclamação da harmonia social e transformação do Estado numa 
simples administração da produção —, todas essas proposições nada fazem do que anunciar o desaparecimento do antagonismo das classes, antagonismo que começa somente a se desenhar e que os inventores de sistemas só conhecem suas primeiras formas indistintas e confusas. Por isso essas proposições têm somente um sentido puramente utópico. (Marx e Engels, 2007, p. 86)

As discussões contemporâneas sobre a relação desses processos têm permitido a visualização de duas estratégias distintas: organizar politicamente trabalhadores empregados e proporcionar uma forma de trabalho não capitalista dentro do sistema capitalista para aqueles que estão desempregado ou à margem do sistema social e produtivo. Ou seja, responder às necessidades imediatas com vista a projeções futuras, segundo afirma Maria Nezilda Culti (2000, p. 118): "Para amenizar a questão do desemprego e oferecer oportunidades para aqueles que estão socialmente excluídos, é importante criar alternativas reais de reinserção na economia por sua iniciativa individual ou coletiva". Uma das questões colocada pelos sujeitos vinculados à perspectiva do socialismo utópico é criar mecanismos para que o trabalhador seja proprietário dos meios de produção e dos resultados obtidos do processo produtivo. Sobre isso Singer afirma que

A economia solidária foi inventada por operários, nos primórdios do capitalismo industrial, como resposta à pobreza e ao desemprego resultantes da difusão "desregulamentada" das máquinas-ferramenta e do motor a vapor no início do século XIX. As cooperativas eram tentativas por parte de trabalhadores de recuperar trabalho e autonomia econômica, aproveitando as novas forças produtivas. Sua estruturação obedecia aos valores básicos do movimento operário de igualdade e democracia sintetizado na ideologia do socialismo. (2005a, p. 83)

Os experimentos e organizações dentro da perspectiva da economia solidária surgiram como proposta de suprimir a desigualdade social, fenômeno característico essencial do sistema capitalista, já que para haver a reprodução do próprio sistema é necessário que exista esse antagonismo. Portanto, a desigualdade social e a exploração são inerentes à lógica capitalista. Sua forma mais extrema é representada pela necessidade de um "exército industrial de reserva ou superpopulação relativa"" (Marx, 1992, p. 125). Estes são trabalha-

1. Segundo Marx o exército industrial de reserva ou superpopulação relativa é composto por três categorias: a) os aptos para o trabalho; b) órfãos e filhos de indigentes; c) degradados, desmoralizados e incapazes de trabalho (Marx, 1992, p. 128). 
dores sem trabalho, ou seja, desempregados, que foram "para as fileiras de supérfluos" (idem, p. 126) devido ao progresso industrial que expulsa os trabalhadores em períodos de crise e os reabsorve em tempos de expansão, ficando, assim, à mercê dessas oscilações. No entanto, devido às necessidades imediatas, esses trabalhadores, se submetem a vender sua força de trabalho por remunerações mais baixas e aceitam atividades precárias, aumentando a taxa de mais-valia (exploração) para o empregador capitalista. Essa superpopulação relativa força a redução de salário e tende a desarticular a classe dos trabalhadores, uma vez que intensifica a concorrência entre os mesmos na busca de postos de trabalho.

As estratégias de organização produtiva que surgiram a partir do socialismo utópico e das formas cooperativas fizeram frente a toda essa realidade nos idos do século XIX, propondo a muitos trabalhadores nova possibilidade de trabalho não explorado, oferecendo-lhes aspectos que foram expropriados pela produção especificamente capitalista. Nessa nova prática econômica, os trabalhadores puderam experimentar os princípios de democracia e igualdade, equidade e solidariedade, e de serem donos de sua própria produção. Além das primeiras cooperativas nascidas na Inglaterra e França como frutos da Revolução Industrial, a Itália experimentou essa forma de organização, inédita na época, chegando a possuir 2.351 cooperativas em 1919, em sua maioria no ramo da construção. Eram pedreiros, britadores, carregadores que trabalhavam autonomamente, sem intermediários (Culti, 2000, p. 121).

Ao longo do século XX, o cooperativismo perdeu fôlego, e várias cooperativas não duraram por muitos anos. Isso devido à "feroz reação da classe patronal e pela declarada hostilidade do governo" (Lechat, 2002), bem como pela experiência do movimento socialista do Leste Europeu (ex-URSS), que concentrou no modelo de economia centralmente planejada suas principais atividades produtivas.

Nessa esteira, também contribuíram para a diminuição das iniciativas de cooperativismo autogestionário as propostas políticas do New Deal após a crise de 1929, desenvolvidas pelo presidente norte-americano F. Roosevelt fundamentadas a partir da teoria keynesiana, que preconizava uma política de pleno emprego, além do controle econômico pelo Estado, e que após a Segunda Guerra Mundial foi retomada como propostas do Welfare State até meados da década de 1960. Alain Bihr afirma que o "compromisso fordista" desenvolvido no início do século XX garantiu os direitos formais e reais da classe 
proletária, prometendo eliminar a "condição proletária" marcada pela miséria, instabilidade, incerteza do futuro e opressão desenfreada (Bihr, 1998). ${ }^{2}$

Como se pode perceber, na investigação histórica, o avanço do ideário cooperativista autogestionário ocorreu em momentos de crise do capital, como as de 1873-98, 1929-32, 1970 e 2008, caracterizados por grande taxa de desemprego. Esse processo é pertinente à própria lógica do capital, uma vez que seu objetivo é o lucro, e tão somente ele. Assim promove a reestruturação da produção e o gerenciamento organizacional com o intuito de recuperar a taxa de lucratividade e para tal objetivo investe em novos modelos de produção.

Enquanto esse processo tenta salvar a lucratividade das empresas, concomitantemente causa um desastre no mundo do trabalho. Devido a esse processo, muitos direitos conquistados pelos trabalhadores são modificados, níveis dos salários são reduzidos, leis de proteção ao trabalhador são remodeladas, fazendo surgir empregos de tempo parcial, terceirizações, trabalhos temporários e informais, ou seja, ampliação da precarização do trabalho, além da alta taxa de desemprego. Esse é um movimento lógico do capital, pois como afirma Mészáros (2009, p.70):

O capital, quando alcança um ponto de saturação em seu próprio espaço e não consegue simultaneamente encontrar canais para nova expansão, na forma de imperialismo e neocolonialismo, não tem alternativa a não ser deixar que sua própria força de trabalho local sofra as graves consequências da deterioração da taxa de lucro.

E a consequência dessa deterioração se resolve com o "enxugamento da empresa", ou transferência dos polos produtivos para localidades onde a força de trabalho é mais barata, ou possui menor regulamentação legal, tudo isso

2. Bihr (1998) afirma que a lógica do desenvolvimento do capitalismo impôs tanto ao proletariado quanto a patronato um acordo tácito que denominou de "compromisso fordista", onde o proletariado "renunciou à sua aventura histórica" em troca das garantias da seguridade social. E o capitalista, por um lado, neutraliza o conflito proletário, no entanto está posto que sua dominação não é absoluta, sendo esse compromisso arbitrado pelo Estado. Tal compromisso ofereceu quase três décadas de crescimento econômico ininterrupto, tanto que o modelo de Ford tornou-se paradigma para a produção industrial. No entanto, a "ruptura do compromisso" é provocada pela crise do capital, ao qual Bihr irá indicar quatro fatores: a) diminuição dos ganhos de produtividade; b) elevação da composição orgânica do capital; c) saturação da norma social de consumo; d) desenvolvimento do trabalho improdutivo. 
vinculado às demissões em massa e aos programas de demissão voluntária (PDV). Portanto, para Mészáros o desemprego é a característica dominante do sistema capitalista, porque está configurado como uma característica estrutural. Nessa fase atual, a onda de desemprego não está restrita tão somente aos países periféricos ou trabalhadores desqualificados, mas todos estão no “fio da navalha”. Já na década de 1970, Mészáros (2006, p. 29; grifos do autor) afirmava que

Como resultado dessa tendência, o problema não se restringe à situação dos trabalhadores não qualificados, mas atinge também um grande número de trabalhadores altamente qualificados, que agora disputam, somando-se ao estoque anterior de desempregados, os escassos - e cada vez mais raro - empregos disponíveis. Da mesma forma, a tendência da amputação "racionalizadora" não está mais limitada aos "ramos periféricos de uma indústria obsoleta", mas abarca alguns dos mais desenvolvidos e modernizados setores da produção.

Tem ocorrido desde o final do século XX uma globalização do desemprego estrutural, seja em países centrais de capitalismo avançado, onde sempre houve a promessa do pleno emprego mediante as benesses do liberalismo político e econômico, seja em países "pós-capitalistas" ou, ainda, nos países periféricos. Por exemplo, há mais de 40 milhões de desempregados nos países industrialmente mais desenvolvidos, a Europa possui mais de 20 milhões e a Alemanha ultrapassa os 5 milhões; na Índia, os números chegam a 336 milhões de desempregados; e a China estima em 268 milhões o total de desempregados (Mészáros, 2006, p. 30).

No Brasil, a onda de desemprego em massa é uma realidade desde a década de 1990, período em que o Brasil assumiu a agenda do neoliberalismo, portanto um compromisso com o livre mercado, desregulamentação das leis trabalhistas e, consequentemente, desestruturação do mercado de trabalho como parte do processo de reestruturação produtiva, nos moldes vistos acima. Márcio Pochmann (2006) compreende o fenômeno do desemprego no Brasil como estrutural, assim como Mészáros, e não decorrente de competitividade empresarial, alto custo de contratação e/ou qualificação inadequada dos trabalhadores, explicação oficial acerca do fenômeno. O individualismo extremado e a competitividade a qualquer custo interferem diretamente na subjetividade dos indivíduos, naturalizando relações de dominação e exploração, tornando latente 
uma classe trabalhadora fragmentada, dificultando a formação da consciência de classe e, consequentemente, sua luta política.

De acordo com o autor, o desemprego estrutural está relacionado à persistência de baixas taxas de expansão da economia brasileira e à evolução de um novo modelo econômico desde 1990. Segundo o referido autor, o Brasil possui uma economia instável que oscila constantemente em sua produção, podendo ser observados períodos de recessão (1981-83, 1990-92, 1998-99, 2002-03), fases de recuperação (1984-86, 1993-97), e de estagnação (1987-1989, 2002). A conclusão de Pochmann é de que o desemprego no Brasil além possuir um caráter estrutural, é também extremamente desigual quando são analisadas as classes de rendimentos, gênero, raça e nível de escolaridade (Pochmann, 2006, p. 72).

Com esse contexto inícial do século XXI, estimular essas novas formas de organização e produção cooperativista (autogestionário, socioeconômico ou solidário) está em consonância com o que

sugere Lefebvre e concorda Heller, a revolução implica mudar a vida. A revolução de modo algum se confunde com o golpe de Estado, com a chamada "tomada do poder". Como já se viu, é possível tomar o poder e não revolucionar nada. Ou melhor, a sociedade toma o poder quando arrebata o Estado, direitos e possibilidades, e também responsabilidades, que lhe foram confiscados por ele, quando assume e realiza por si mesma, sem intermediários, a compreensão e a gestão de suas necessidades. Isso implica profundas mudanças na vida, isto é, no viver, no modo de viver. É aí que se situa o núcleo da criatividade social, da invenção do novo a partir das possibilidades abertas pela práxis. (Martins, 2000, p. 163)

Nesse sentido, estudar, conhecer, analisar e interpretar os experimentos que se desenvolvem no campo do referido cooperativismo é também um exercício teórico-prático que colabora e difunde uma nova consciência, um novo saber e estimula a participação dos sujeitos no processo histórico emancipatório e criador. Por esse motivo, é necessário aprofundar o debate em torno da perspectiva reinventada da economia solidária.

\section{A economia solidária e o cooperativismo}

Segundo a Organização das Cooperativas Brasileiras (OCB), o cooperativismo é um modelo socioeconômico que objetiva o desenvolvimento econômi- 
co aliado ao bem-estar social. Seus princípios são participação democrática, solidariedade, independência e autonomia. ${ }^{3}$

O cooperativismo se divide em categorias que ilustram suas funções no mercado, como as cooperativas de consumo, de crédito, de compra e venda e de produção. $\mathrm{O}$ grande diferencial das cooperativas vinculadas à perspectiva da economia solidária e não configuradas como empresas capitalistas é o modo de sua administração. As primeiras possuem sua administração pautada na autogestão, enquanto as segundas praticam a heterogestão (Singer, 2008, p. 16).

No entanto, Pinto (2006, p. 29) afirma que a concorrência dos empreendimentos capitalistas e o excesso de burocratização promoveram uma descaracterização das cooperativas, transformando-as em empresas capitalistas, assalariando a maioria da força de trabalho. Nas empresas e cooperativas capitalistas existe a administração hierárquica, isto é, o poder de controle acontece em níveis sucessivos. Os funcionários de menor importância para a instituição pouco sabem sobre a empresa na qual trabalham, conforme a hierarquia aumenta, seu conhecimento amplia-se em igual proporção. A dificuldade oriunda dessa forma administrativa surge quando a competição entre setores prejudica a própria corporação. Como elucida Singer, os empregados devem competir entre si para que sua produtividade seja alta e garantam o próprio emprego, ao mesmo tempo em que cooperam entre os setores para que a empresa prospere. Nessa contradição, a heterogestão se transforma constantemente em busca da maneira mais efetiva de extrair a maior quantidade de trabalho e eficiência de seus funcionários (Singer, 2008, p. 16-18).

Já a autogestão é verificada nas cooperativas solidárias. O princípio da autogestão é, como o próprio nome sugere, a administração da cooperativa operada pelos seus donos, isto é, os cooperados. Se a cooperativa possui poucas pessoas, as decisões são tomadas por todos por meio das assembleias gerais. No entanto, se a cooperativa possui sócios em maior número e a assembleia não é um recurso viável, opta-se pela delegação de poder a cada setor, e estes decidem conjuntamente o destino da cooperativa. Na cooperativa - e a grande diferença reside aqui —, todos devem estar informados a respeito dos fatos

3. Disponível em: <http://www.ocb.org.br/site/cooperativismo/institucional.asp $>$. Acesso em: $1^{\circ}$ dez. 2009. 
ocorridos, pois cada um é responsável pelo desenvolvimento dessa organização. A autogestão exige um empenho extra, entretanto não é necessário o incentivo constante de seus sócios a partir da competição.

Existem problemas no processo de autogestão, porque pode se tornar desgastante a discussão frequente de cada passo da cooperativa, além de a falta de interesse dos sócios trazer sérios riscos à organização. É preciso, por parte dos sócios, desejo de participar da cooperativa, além de interesse na luta por um modo de produção mais justo, pois além de lhes conferir sua subsistência financeira, a autogestão confere desenvolvimento humano a quem a pratica (Singer, 2008, p. 18-21).

Comparar os dois tipos administrativos é uma temática nula, pois elas se diferenciam em seu fim. Enquanto a heterogestão objetiva o lucro, intenção de seus praticantes, a autogestão procura dar às cooperativas solidárias viabilidade econômica, além de democracia e igualdade, e proporcionar a inclusão cada vez maior de trabalhadores. Como atesta Boaventura de Sousa Santos, os benefícios da economia solidária vão muito além do econômico: “As cooperativas de trabalhadores geram benefícios não econômicos para os seus membros e para a comunidade em geral, que são fundamentais para contrariar os efeitos desiguais da economia capitalista" (Santos, 2002, p. 37).

Segundo Singer (2008), a cooperativa de Mondragón, maior complexo cooperativo do mundo, é o exemplo vivo da viabilidade da economia solidária. Fundada em 1956, na cidade basca de Mondragón, Norte da Espanha, por iniciativa de José Maria Arizmendiarreta, a corporação combina cooperativas de produção industrial e de serviços comerciais e conta ainda com um banco cooperativo, uma cooperativa de seguro social e uma universidade. Para o autor, o que torna Mondragón ainda mais notável é a aplicação coerente dos princípios do cooperativismo e da autogestão: todos os que trabalham são proprietários e todos os proprietários trabalham na cooperativa.

O Complexo Cooperativo de Mondragón conta com mais de 250 cooperativas associadas e está presente em países como Brasil, China, Índia, México, Rússia e Estados Unidos, somando aproximadamente 70 mil associados. A maior parte dos trabalhadores não sócios estão na forma transitória, já que geralmente se tornam sócios cooperativistas no prazo de dois a três anos. ${ }^{4}$

4. Disponível em: <www.portaldocooperativismo.org.br $>$ e $<$ www.ica.coop/al-ica/ $>$. Acesso em: $1^{\circ}$ dez. 2009. 
Um dos pontos fortes de Mondragón, além da motivação gerada pelo ambiente de cooperação, é o fato de possuir uma abordagem empresarial na busca continua por eficiência. Ao reinvestir quase a totalidade dos recursos no complexo cooperativo, dão destaque para a pesquisa e o desenvolvimento, visando inovação permanente, bem como no que diz respeito à educação para o cooperativismo, o que impõe um esforço adicional na formação por meio da universidade própria.

\section{A economia solidária e o cooperativismo no Brasil}

O cooperativismo surgiu no Brasil no início do século XX, quando emigrantes europeus trouxeram as primeiras experiências e puderam enfrentar as adversidades de um novo mundo. Uniam as suas parcas economias e seus conhecimentos em modelos organizacionais que potencializavam os seus esforços, o que resultou em expressivo vigor econômico e social para as regiões onde eles se estabeleceram. As cooperativas, no início do século, tomaram forma, principalmente, de consumo e agrícolas, sendo que estas últimas tiveram maior desenvolvimento, já que as de consumo acabaram, anos mais tarde, sendo compradas por mercados de grande porte. Todavia, é necessário salientar que essas iniciativas, ainda que cooperativistas, pouca vezes praticaram a autogestão (Singer, 2008, p. 122).

Embora o cooperativismo tenha enfrentado dificuldades ao longo de todo o século XX, mostrou-se capaz de resistir e de se firmar na economia nacional. Todavia, alguns dos princípios originais dessa modalidade organizacional sofreram alterações e muitas vezes fizeram com que esses empreendimentos passassem a ter um perfil muito próximo das empresas capitalistas tradicionais. No final do século XX, como resposta à crise do emprego e amparada nos ideais fundamentais do cooperativismo de autogestão surgiu no Brasil o movimento da economia solidária, como atesta Singer (2000, p. 25):

A economia solidária começou a ressurgir, de forma esparsa na década de 1980 e tomou impulso crescente a partir da segunda metade dos anos 1990. Ela resulta de movimentos sociais que reagem à crise de desemprego em massa, que tem seu inicio em 1981 e se agrava com a abertura do mercado interno às importações, a partir de 1990. 
O empreendimento de economia solidária no Brasil foram se organizando por meio de várias frentes e estímulos, como vinculados a Universidades em Incubadoras Tecnológicas de Cooperativas Populares (ITCPS), assim como a criação da Secretaria Nacional de economia solidária (Senaes) e o Fórum Brasileiro de economia solidária (FBES), que se estruturaram de forma a garantir a articulação entre três segmentos do movimento de economia solidária: empreendimentos solidários, entidades de assessoria e fomento, e gestores públicos.

Deve se levar em conta que existem inúmeras modalidades de cooperativismo que não estão vinculadas à economia solidária e, dessa, forma têm que ser analisadas sob diferentes perspectivas. A partir da contribuição de Lima (1998, p. 4) esses empreendimentos podem ser classificados em diversas categorias, a saber:

- Cooperativas de produção ou de trabalho: surgem no curso histórico em momentos críticos da economia, existindo em limitado espaço de tempo. Os trabalhadores das cooperativas de trabalho prestam serviços às indústrias em troca de um valor em dinheiro, distanciando-se dos funcionários assalariados apenas no que tange à ausência dos direitos consolidados dos trabalhadores; pode ser uma forma de burlar os direitos trabalhistas. Todavia, a parceria com órgãos públicos pode modificar esse quadro, se aliado a projetos de geração de renda, pois podem trazer benefícios em um espaço de tempo curto. Ainda que sua continuidade não seja garantida, seus aspectos positivos permanecem como a atração de investimentos, inserção social dos cidadãos e a manutenção dos indivíduos em suas cidades de origem.

- “Cooperfraudes" ou "pseudocooperativas": na experiência brasileira, é um negócio organizado pelos empregadores que direcionam toda contratação de mão de obra a partir de tais cooperativas de prestação de serviços. No entanto, são organizadas pelos representantes dos empregadores para contratar sem ter obrigações trabalhistas e com menor remuneração, o que na realidade é ilegal. Esse modelo de contratação intensifica os processos de precarização das condições de trabalho e contribui para a constituição de experiências negativas na história do cooperativismo no Brasil. 
- Cooperativas que atuam como empresas capitalistas: nos mais diferentes setores da economia são constituídas as formas de organização cooperativa que possuem dentro dos princípios do cooperativismo uma diversidade de relações entre os cooperados, bem como entre seus funcionários. São organizações com estatutos e regimentos internos que normatizam a gestão, com participação e distribuição de sobras aos sócios, e que ao mesmo tempo são grandes empregadoras de mão de obra assalariada, tendo em vista que não estão enquadradas na perspectiva da economia solidária.

- Cooperativas agrícolas ou agroindustriais na perspectiva da economia solidária: esta última forma de cooperativismo é a que nos interessa para delimitarmos a discussão desenvolvida até o momento, as formas de organizações produtivas desenvolvidas no campo na perspectiva da economia solidária. ${ }^{5}$

As cooperativas de trabalhadores rurais, que possuem seus minifúndios e se organizam em "experiências de geração de trabalho e renda, de forma solidária e associativa [...] passam a dar lugar, gradativamente, a uma realidade que se expande e se dinamiza, motivando ações de entidades de classe e de políticas públicas no campo popular, orientadas para uma economia alternativa concreta que está em processo de gestação" (Eid, 2001, p. 3). Esses experimentos vinculados à economia solidária no campo conquistaram nas últimas duas décadas um saber inovador aplicado no campo produtivo, social e ambiental. É verdade que nem todas as cooperativas obtiveram sucesso e longevidade, tendo em vista que nem todos os integrantes conseguem ultrapassar a forma de pensamento individual, a leitura da realidade a partir do valores predominantes da economia capitalista e machista. No entanto, muitas experiências foram fortalecidas e produziram essa nova forma de produção e sociabilidade entre seus cooperados.

5. Ver também já foi desenvolvida pelo "O ciclo de debates sobre cooperativismo foi um evento promovido pelo programa ‘UFSCar 30 Anos', pelo Núcleo de Extensão UFSCar-Cidadania/Proex, pela Incubadora Regional de Cooperativas Populares/Proex e pelo Departamento de Engenharia de Produção, com o apoio do Ministério da Justiça e da Unesco" em 2000 e sintetizado e publicado por Farid Eid. Disponível em: $<$ http://www.unitrabalho.org.br/imagens/artigos/set05/CAPLIVRO_UFSCAR.pdf $>$. Acessado em: 2 fev. 2010. ver Valêncio, Norma, 2001. 
Assim, o desenvolvimento desse cooperativismo permitiu uma nova racionalidade dentro do próprio sistema capitalista e, ao mesmo tempo, ultrapassa a condição de improvisação, falta de planejamento ou tradicionalismo que marcam o cotidiano das pequenas e médias propriedades rurais brasileira.

Dentro desse panorama, a organização da produção e do trabalho assume importante papel para o desenvolvimento de um assentamento. Onde existe maior organização política dos assentados, foi garantido um melhor acesso às políticas públicas sociais e produtivas. Do mesmo modo, nos assentamentos analisados, onde havia falta de organização política, resultou em baixa capacidade de interlocução com os diversos órgãos públicos, bem como na falta de organização produtiva, o que poderia permitir uma utilização mais racional dos investimentos e na potencialização dos sistemas produtivos. (Eid, 2001, p. 8)

É importante compreender que os experimentos que se desenvolveram no campo não seguiram uma cartilha ou regra pronta. Tal qual já foi destacado no início deste artigo, as diversas formas de organização dentro dos princípios da economia solidárias se constituíram nas mais diferentes realidades e processos sócio-históricos. Nos assentamentos pesquisados, há várias formas de organização e gestão dessa nova forma coletiva de ser e de ter, e

a cooperação pode iniciar com as formas mais simples tais como: mutirão, troca de serviços e/ou de insumos, grupos de trabalho coletivo, semicoletivos e associações prestadoras de serviço e ir evoluindo, aos poucos, em direção a formas mais desenvolvidas de cooperação, como as Cooperativas de Prestação de Serviços (CPS), as Cooperativas de Produção e Prestação de Serviços (CPPS), Cooperativas de Crédito e as Cooperativas de Produção Agropecuária (CPA’s). (Eid, 2001, p. 9)

Dentro dessa abordagem e sem dar conta de todo o universo que se constituiu nas últimas décadas, selecionamos como dado da realidade um exemplo que aponta alguns elementos para reflexão sobre os processos de desenvolvimento das cooperativas (autogestionárias, solidárias ou socioeconômicas) e que auxilia na construção de um novo saber sobre a temática. É uma aproximação das discussões apresentadas e que serviu para a pesquisa de campo com visita in loco. Trata-se da experiência da Cooperativa de Produção Agropecuária 
Vitória Ltda. (Copavi), com sede no município de Paranacity, a 110 quilômetros de Maringá, na região noroeste do estado do Paraná, e tem aproximadamente 6 mil habitantes.

O assentamento Santa Maria, onde está organizada a Copavi, conta com 98 pessoas (adultos e crianças), num total de 22 famílias. Segundo o cooperado Élson Borges dos Santos — popularmente conhecido como Zumbi,

produzimos trinta toneladas de açúcar mascavo [orgânico] por mês, distribuídas em catorze estados. Temos um rebanho de gado leiteiro de 250 cabeças, produzimos queijo, iogurte, leite, rapadura, hortaliças, verduras, pães e também cachaça, cerca de 150 mil litros por ano, e boa parte dessa produção é exportada. (Yudi, $2007)^{6}$

A estrutura organizativa da Copavi, segundo a cooperada Joelci Dannacena, compreende diferentes órgãos. É composta pelo Conselho Deliberativo com cinco membros ${ }^{7}$ com fórum de discussão semanal, onde são debatidos assuntos de ordem cotidiana. As famílias são organizadas em dois núcleos, que fazem reuniões mensais, e as discussões envolvem a prestação de contas, questões de ordem social e mesmo assuntos que serão encaminhados para as assembleias. O órgão máximo da cooperativa é a Assembleia Geral, que se reúne mensalmente, define as diretrizes, estratégias, projetos e atividades da Copavi. Essa caracterização é reforçada por Joelci Dannacena, ao indicar que "o diferencial que faz com que a cooperativa venha a ser um empreendimento ao mesmo tempo econômico, de geração de renda e de inclusão social, sem dúvida é a autogestão".

6. Para maior aprofundamento, acessar a reportagem publicada In: Notícia — semanário da Agência de Comunicação da UEL, publicada em 29/8/2007, edição n. 1137, p. 6-7. Disponível em: <http://www2.uel. br/com/noticiadigital/index.php?arq=ARQ_jnt\&FWS_Ano_Edicao=1\&FWS_N_Edicao=1\&FWS_N_ Texto $=5314 \&$ FWS_Cod_Categoria=15>. Acesso em: 8 fev. 2010. Ou a matéria publicada no blog Economia Solidária e Agroenergia. Disponível em: <http://economiasolidariaeagroenergiaparana.blogspot.com/2008/05/ o-secretrio-de-economia-solidria-do.html>. Acesso em: 8 fev. 2010.

7. O Conselho Deliberativo é composto por três representantes dos coordenadores dos setores e dois da representação dos núcleos de família. Exemplifica outro cooperado, o sr. Franscisco Stronzak: “ “... tem o que coordena a pecuária de leite, outro que coordena a indústria de canas, daí tem o comércio, cozinha, panificadora, $[. .$.$] o pessoal da horta, daí os coordenadores desses setores [possuem seus representantes que] também$ formam o Conselho Deliberativo" (Stronzak, 2010). 
Nesse processo de gestão, os cooperados da Copavi realizam em seu cotidiano uma participação democrática direta e promovem uma nova forma de sociabilidade, bem como produzem uma práxis pedagógica que contribui para a formação dos adultos, jovens e crianças.

Segundo o cooperado Franscisco Stronzak, uma das dificuldades de agregar novas famílias é a cultura do brasileiro, isto é, a cultura individualista característica da sociedade capitalista. A grande maioria das pessoas pensa: “... eu tenho que ter uma vaca que é minha, eu tenho que ter um lote de terra que é meu, que ali eu faço o que eu quero, e aqui [Copavi] é administrado pelo grupo" (Stronzak, 2010). Na Copavi, a perspectiva é a valorização do coletivo, "tem que aprender a falar [...] o nosso, chega aqui, nós falamos, são nossas vacas, nosso trator" (Stronzak, 2010).

Nesse trajeto, novas formas de sociabilidade foram constituídas. Ele ainda esclarece que apesar do esforço continuo que deve ser empregado na cooperativa por parte dos cooperados, a estrutura que existe na Copavi oferece as condições necessárias para a vida dos mesmos. Stronzak (2010) ilustra dizendo que além do adiantamento mensal das sobras resultantes do fechamento contábil anual, a cooperativa proporciona "a questão da alimentação; tem a horta, o leite, a carne, o doce, já tem cachacinha”.

Dessa forma, o homem e a mulher do campo alçaram voo por horizontes desconhecidos, tendo em vista o processo de formação sócio-histórico brasileiro, ultrapassaram a barreira do individualismo (que fragiliza os pequenos produtores), os valores machistas, porque as mulheres participam do processo decisório, e possuem voto nas assembleias das cooperativas e muitas vezes aliaram o saber tradicional da produção no campo com as novas formas de tecnologia produtivas e gerenciamento.

Esse exercício de valorização da propriedade coletiva e das formas de gestão das mesmas tem referências históricas e são o contraponto à ideia liberal de propriedade privada. Essa discussão ganhou novo fôlego a partir do prêmio Nobel de Economia de 2009, quando foi concedido a Elinor Ostrom ${ }^{8}$ por suas pesquisas sobre "governança econômica".

8. Ver matéria do Conselho Federal de Economia. Disponível em: $<$ http://www.cofecon.org.br/index. php?option=com_content\&task=view\&id=1899\&Itemid=51>. Acesso em: 8 fev. 2010. 
A Academia Sueca citou a importância de Elinor [...] dizendo que seu trabalho demonstrou como a propriedade comum pode ser gerenciada com sucesso por associações. Elinor Ostrom desafiou o conhecimento convencional com estudos demonstrando que propriedades administradas por usuários, como áreas madeireiras e ativos de pesca, eram frequentemente melhor administradas do que as teorias padrão previam. A visão anteriormente aceita era de que a propriedade comum era mal gerenciada e deveria ser centralmente regulada ou privatizada. ${ }^{9}$

Estudos de governança econômica - Elinor Ostrom estudou a administração de propriedades coletivas por grupos de proprietários, contrastando com a administração de instituições governamentais e privadas. Baseada em estudos sobre estoques de peixes, pastagens, florestas, lagos e bacias subterrâneas administradas pelos usuários, Ostrom descobriu que os resultados muitas vezes são melhores que os previstos pelas teorias-padrão. Observou também que os usuários de recursos frequentemente desenvolvem sofisticados mecanismos para lidar com conflitos de interesse e tomadas de decisão, caracterizando as regras que promovem resultados positivos. Em resumo, a autogovernança pode ter sucesso. (Castanho, 2009) $)^{10}$

Tendo em vista a conjuntura da crise global detonada em 2008, a ampliação permanente das taxas de desemprego, os processos de reestruturação produtiva e a precarização das condições de trabalho, associado a "insegurança social [como] uma das faces do custo social da informalidade, resultante das mudanças ocorridas no processo de acumulação do capital, que, por sua vez, afetaram as relações entre Estado, mercado e sociedade" (Lira, 2008, p. 153), o prêmio Nobel de Economia em 2009 trouxe à tona o reconhecimento dado às formas de organização coletiva como estratégia de gestão, produção, conservação e sobrevivência dos grupos envolvidos e do meio ambiente.

Encaminhando as análises, é possível afirmar que o caminho traçado pelas diversas experiências da economia solidária (socioeconomia ou cooperativismo autogestionário) e seus benefícios coletivos são uma aposta e a possibilidade

9. Disponível em: $<$ http://oglobo.globo.com/economia/mat/2009/10/12/dois-americanos-dividem-nobelde-economia-2009-uma-mulher-ganha-pela-primeira-vez-768018974.asp publicada em 12/10/2009>. Acesso em: 8 fev. 2010.

10. Manoel Castanho, jornalista do Conselho Federal de Economia (Cofecon). Disponível em: $<$ http:// www.cofecon.org.br/index.php?option=com_content\&task=view\&id=1899\&Itemid=51>. Acesso em: 8 fev. 2010 . 
de exercitar novas demandas humanas e ambientais distanciadas das práticas capitalistas já conhecidas e desenvolvidas pela iniciativa privada, pelo mercado e pelo Estado.

\section{Considerações finais}

Na conjuntura nacional do início do século XXI, em que há uma combinação de elevação da taxa de desemprego e desemprego estrutural, de precarização das condições de trabalho, de reformas trabalhistas que promovem a terceirização e a subcontratação da mão de obra, com a consequente ampliação da informalidade e do estímulo às estratégias de "empreendedorismo empresarial" no qual o trabalhador passa a ser o único responsável pelo sucesso ou fracasso do seu novo negócio, somados ainda à desarticulação da classe trabalhadora em geral, sem sindicatos combativos e que busquem a radical transformação a partir do capitalismo, a perspectiva cooperativista abordada (autogestionária, socioeconômica, solidária) tornou-se:

a) possibilidade de conquista de melhores condições objetivas de vida (alimentação, moradia, renda, educação, convívio comunitário, articulação política, entre outros) para muitas pessoas que já estavam à margem do sistema produtivo capitalista (como por exemplo no segmento dos trabalhadores da coleta seletiva e reciclagem urbanos ou assentados rurais do programa de Reforma Agrária);

b) um campo de formação de uma nova cultura, em que os participantes por livre adesão, rompem com a hegemonia individualista norteadora dos dias atuais, em que ocorre a assimilação ao processo socioeducativo oriundo da vida coletiva, da participação nas assembleias ou mesmo do contato com os profissionais (administradores, agrônomos, assistentes sociais, contadores, sociólogos, pedagogos, profissionais da saúde...) que atuam nas políticas públicas de fomento e assessoria dos experimentos de economia solidária;

c) um microespaço de formulação de uma contra-hegemonia capitalista, que poderá ser significativo para a instalação de um outro projeto societário, onde as relações sociais produtivas estejam subordinadas às 
demandas sociais e ambientais, e não ao lucro individualizante e concentrador;

d) uma estratégia a partir dos subalternizados, e não dos incluídos nos benefícios do lucro e da condição de estratos médios da sociedade, de possibilidade de mudança a longo prazo do panorama atual de descrença absoluta no ser humano e na sua capacidade de reflexão, mobilização e viabilização de novos projetos e utopias.

Ao identificar vários aspectos destacados ao longo deste estudo, alguns eixos centrais são colocados como desafios na busca dessa forma de organização produtiva autogestionária, democrática e solidária: o interesse dos sujeitos envolvidos e a clareza do projeto a seguir; a articulação entre a mobilização social desses sujeitos e as políticas públicas, bem como a importância da assessoria técnica; o papel das universidades no contexto regional; e a importância da compreensão do valor da propriedade coletiva e a conquista dos benefícios na mesma forma.

Essa busca de sobrevivência e novas formas de vivência e educação coletiva são relevantes no contexto mundial. Os homens e mulheres "simples" estão cristalizando uma nova sociabilidade a partir das formas objetivas de produção e geração de renda, bem como pela difusão de novos valores culturais, sociais e ambientais.

Artigo recebido em ago/2010 - Aprovado em dez./2010

\section{Referências bibliográficas}

BIHR, Alain. Da grande noite à alternativa. São Paulo: Boitempo, 1998.

CULTI, Maria Nezilda. Sócios do suor: cooperativas de trabalho. In: PRIORI, Angelo (Org.). O mundo do trabalho e a política: ensaios interdisciplinares. Maringá: Eduem, 2000. p. 113-137.

EID, Farid. Cooperativismo de reforma agrária e direitos humanos no Brasil. In: VALÊNCIO, Norma (Org.). Caminhos da Cidadania: um percurso universitário em prol dos direitos humanos. São Carlos: Editora UFSCar, 2001. 
LECHAT, Noëlle Marie Paule. As raízes históricas da economia solidária e seu aparecimento no Brasil. Palestra proferida na Unicamp por ocasião do II Seminário de Incubadoras Tecnológicas de Cooperativas Populares, em 20/3/2002. Disponível em: $<\mathrm{http} / / / w w w . i t c p . u s p . b r / d r u p a l / n o d e / 250>$. Acesso em: 13 nov. 2009.

LIMA, Jacob Carlos. Desconcentração industrial e precarização do trabalho: cooperativas de produção do vestuário no Brasil, 1998. Disponível em: $<$ http://bibliotecavirtual.clacso.org.ar/ar/libros/lasa98/Lima.pdf> .

LIRA, Izabel Cristina Dias. Trabalho informal como alternativa ao desemprego: desmitificando a informalidade. In: SILVA, Maria Ozanira da Silva; YAZBEK, Maria Carmelita. Políticas públicas de trabalho e renda no Brasil contemporâneo. 2. ed. São Paulo: Cortez; São Luiz: Fapema, 2008. p.130-160.

MARTINS, José de Souza. A sociabilidade do homem simples. São Paulo: Hucitec, 2000.

MARX, Karl. Salário, preço e lucro. São Paulo: Abril, 1974. p. 61-105. (Col. Os Pensadores.)

. Classes sociais e contradição de classes. In: IANNI, Otávio. Karl Marx. São Paulo: Ática, 1992. (Col. Pensadores.)

; ENGELS, Friedrich. Manifesto do Partido Comunista. São Paulo: Escala, 2007.

MÉSZÁROS, István. Desemprego e precarização: Um grande desafio para a esquerda. In: ANTUNES, Ricardo (Org.). Riqueza e miséria do trabalho no Brasil. São Paulo: Boitempo, 2006, p. 27-44.

. A crise estrutural do capital. São Paulo: Boitempo, 2009.

PINTO, João Roberto Lopes. Economia solidária: de volta à arte da associação. Porto Alegre: Editora da UFRGS, 2006.

POCHMANN, Márcio. Desempregados no Brasil. In: ANTUNES, Ricardo (Org.). Riqueza e miséria do trabalho no Brasil. São Paulo: Boitempo, 2006. p. 59-73.

SANTOS, B. de S. (Org.). Produzir para viver: os caminhos da produção não capitalista. Rio de Janeiro: Civilização Brasileira, 2002.

SINGER, Paul. A recente ressurreição da economia solidária no Brasil. In: SANTOS, Boaventura Souza (Org.). Produzir para viver: Os caminhos da produção não capitalista. Reinventar a emancipação social: para novos manifestos; 2. Rio de Janeiro: Civilização Brasileira, 2005a. p. 81-129. 
SINGER, Paul. Introdução. In: MELLO, Sylvia Leser de (Org.). Economia solidária e autogestão: encontros internacionais. São Paulo: Nesol, ITCP e PW, 2005b.

2008.

Introdução à economia solidária. São Paulo: Editora Fundação Perseu Abramo,

; SOUZA, André R. de. A economia solidária no Brasil: A autogestão como resposta ao desemprego. São Paulo: Contexto, 2000.

STRONZAK, Francisco. Depoimento coletado na visita à Copavi em março de 2010, Paranacity (PR).

YUDI, Chico. Zumbi, dos sem-terra, dá aula na pós-graduação. Notícia. Londrina: Universidade Estadual de Londrina, n. 1.137, ago. 2007, p. 6-7.

VALÊNCIO, Norma (Org.). Caminhos da Cidadania: um percurso universitário em prol dos direitos humanos. São Carlos: Editora UFSCar, 2001.

\section{Referências digitais}

$<$ http://www.mte.gov.br/imprensa/homenagem/23_paul_singer.asp $>$ e http://www. brazil-brasil.com/content/view/259/111/>. Acesso em: 23 jan. 2010.

$<$ http://www.mte.gov.br/ecosolidaria/sies.asp $>$.

$<$ http://www.ocb.org.br/site/cooperativismo/institucional.asp $>$.

$<\mathrm{http}: / /$ www.mondragon-corporation.com/>.

$<$ http: <www.portaldocooperativismo.org.br $>$ e $<$ www.ica.coop/al-ica/ $>$. Acesso em: $1^{\mathrm{o}}$ dez. 2009.

$<$ http://www.forumepsriogrande.org/?pagina=principal>. Acesso em: 15 nov. 2009.

$<$ http://www.unitrabalho.org.br/imagens/artigos/set05/CAPLIVRO_UFSCAR.pdf $>$. $<$ http://www2.uel.br/projetos/trialogos/mst/MST19.htm>. Acesso em: 8 fev. 2010. $<$ http://www2.uel.br/com/noticiadigital/index.php?arq=ARQ_jnt\&FWS_Ano_

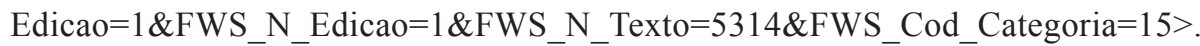
Acesso em: 8 fev. 2010. Ou a matéria publicada no blog Economia Solidária e Agroenergia. Disponível em: $<\mathrm{http} / /$ economiasolidariaeagroenergiaparana.blogspot.com/2008/05/ o-secretrio-de-economia-solidria-do.html>. Acesso em: 8 fev. 2010.

$<$ http://www2.uel.br/projetos/trialogos/mst/MST2.htm>. Acesso em: 8 fev. 2010. 
$<$ http://www.cofecon.org.br/index.php?option=com_content\&task=view\&id=1899\&I temid $=51>$. Acesso em: 8 fev. 2010.

$<$ http://oglobo.globo.com/economia/mat/2009/10/12/dois-americanos-dividem-nobelde-economia-2009-uma-mulher-ganha-pela-primeira-vez-768018974.asp> publicada em 12 de outubro de 2009. Acesso em: 8 fev. 2010.

$<$ http://www.cofecon.org.br/index.php?option=com_content\&task=view\&id=1899\&I temid=51>. Acesso em: 8 fev. 2010. 